\title{
Impact of Climate Variability on Cassava Yield in the Humid Forest Agro-Ecological Zone of Nigeria
}

*ADEJUWON, JO; OGUNDIMINEGHA, YG

\author{
Department of Water Resources Management and Agrometeorology, Federal University of Agriculture, Abeokuta, Nigeria \\ *Corresponding Author Email: adejoseph2003@yahoo.com
}

\begin{abstract}
This study examined cassava yield response to variable climate in the humid forest agro-ecological zone of Nigeria. The data employed for this study was sourced from the archives of Nigeria Meteorological Agency, Lagos State and Ogun State Agricultural Development Program, Abeokuta. Bivariate correlation, multiple regression and Z-distribution were employed for data analysis. Results show that monthly, seasonal and annual rainfall did not affect the yield of cassava but monthly, seasonal and annual minimum and maximum temperature was significantly related to cassava yield at $\mathrm{p} \leq 0.05$. Non-climatic factors have a greater influence on cassava yield than climatic factors in the study area. Nevertheless, climatic factors influenced cassava yield more at Abeokuta than Ijebu-Ode. Cassava yield was lower from 1987-1993 (with negative significant impact in 1987 and 1988 at $\mathrm{p} \leq 0.01$ ) than 1994-2012. These results demonstrated that climate variability needs to be taken into account in cassava impact assessment.
\end{abstract}

DOI: https://dx.doi.org/10.4314/jasem.v23i5.21

Copyright: Copyright (C 2019 Adejuwon and Ogundiminegha. This is an open access article distributed under the Creative Commons Attribution License (CCL), which permits unrestricted use, distribution, and reproduction in any medium, provided the original work is properly cited.

Dates: Received: 21 April 2019; Revised: 23 May 2019; Accepted 25 May 2019

Keywords: cassava yield, impact, climate variability, rainfall, temperature

Variability of agricultural yield depends on weather and climate. Rainfall, temperature, humidity and sunshine (day length) are important climatic elements that influence cropping production (Sowunmi and Akintola, 2010). The overall predictability of these climatic elements is imperative for the day-to-day and medium term planning of farm operations. Other factors that influence the variability of agricultural yield include adoption of common high-yielding varieties, uniform planting practices, common timing of field operations, soil nutrients, and increased fertilizer use (Tollini and Seagraves, 1970; Hazell, 1984; Anderson and Hazell, 1987; Roumasset et al., 1987; Nwaobiala and Nwosu, 2014). Thus, to improve the production of any crop it is important to identify the climatic factors that affect the agricultural segment. Cassava (Manihot esculenta) is a perennial woody shrub with an edible root, which grows in tropical and subtropical areas of the world (Onyenwoke and Simonyan, 2014). It is among several root crop varieties and is one of the main root crops growing in many developing countries located in a low latitude region (Sangpenchan, 2009). Portuguese traders introduced cassava to Africa from Brazil in the 16th century (Okigbo, 1980). It was initially adopted as a famine-reserve crop. In the Democratic Republic of Congo where the crop was first introduced, millet, banana and yam were the traditional staples but farmers adopted cassava because it provided a more reliable source of food during drought, locust attack and during the hungry season. Cassava is grown throughout the year, making it preferable to the seasonal crops of yam, beans or peas (Ajayi, 2014). It displays an exceptional ability to adapt to climate change with a tolerance to low soil fertility, resistance to drought conditions, pests and diseases, and suitability to store its roots for long periods underground even after they mature. The importance of cassava lies in its diverse use as food, fiber and energy sources. The cassava root can be transformed into several end products both by food industries (e.g. pellets, chips, flour, sweetener etc.) and non-food industries (e.g. bio-ethanol) (Sangpenchan, 2009). As a cash crop, Cassava generates cash income for the largest number of households in comparison to other staples. It is very rich in carbohydrates and can be produced all year round. The world cassava output shows Africa as the major producer, with Nigeria consistently been ranked as the world's largest producer since 2005 (FAOSTAT, 2012). Other top producers are Indonesia, Thailand, the Democratic Republic of Congo and Angola. Nigeria output was 36,822 million tones in $2009,42,533$ million tones in 2010 and estimated to be 52,403 million tones in 2011 and 57564 million tones in 2012 respectively (FAO, 2012). Comparing the output of various crops in 
Nigeria, cassava production ranks first, followed by yam production at 27 million tones in 2002, sorghum at 7 million tones, millet at 6 million tones and rice at 5 million tones (FAO, 2004).

Despite the fact that cassava plant grows and produces well in the Nigerian environment, it has shown different growth behaviour and yield in different years as a result of differences in the annual weather condition (Enete, 2003). This is because climate variability has possibility of degrading soil and water resources and subsequently subsistence agricultural production, which is largely practiced by root and tuber crops farmers (Nwaobiala and Nottidge, 2013; Nwaobiala and Nwosu, 2014; Pidwirny and Sidney, 2007). Ogun state is one of the leading cassava producing states in Nigeria and is sensitive to climatic variability most especially rainfall and temperature. The impact of climatic variation on cassava yield in the humid forest agro-ecological zone of Nigeria with particular reference to Ogun State is yet to be carried out, hence this study. The objectives are to: identify and assess the significance of the climatic variables responsible for changes in cassava yield; determine the proportion of cassava yield variability that can be ascribed to climate variability; and assess the impact of the climatic conditions on cassava yield over the period of assessment.

\section{MATERIALS AND METHODS}

The Study Area: The study area, Ogun State is situated between latitudes $6.2^{\circ} \mathrm{N}$ and $7.8{ }^{\circ} \mathrm{N}$ and longitude $3.0^{\circ} \mathrm{E}$ and $5.0^{\circ} \mathrm{E}$ (Fig. 1 \}. It covers a total area of $16,409.26 \mathrm{sq} \mathrm{km}$. It is part of the humid forest agro-ecological zone of Nigeria. Ogun state is located in the moderately hot, humid, tropical climatic zone of southwestern Nigeria. It enjoys a tropical climate governed by the Intertropical Discontinuity (ITD). The ITD marks the boundary line between two air masses - tropical maritime air mass (mT) reaching the land from the gulf of Guinea and the tropical continental air mass (mT) which originates from the Sahara desert (Adejuwon, 2016). Rain falls when an area is under the influence of the tropical maritime (mT) air mass, while dryness prevails when an area is dominated by the tropical continental air mass (cT). The wet season is from March to October and dry season is from November to February. The average rainfall ranges from 1016 to $1270 \mathrm{~mm}$ while the annual temperature is $27^{\circ} \mathrm{C}$.

Data Collection and Analysis: Rainfall and temperature data from 1987 to 2012 was used for this study. The data were obtained from the archive of the Nigerian Meteorological Agency (NIMET) Oshodi, Lagos state, Nigeria. Cassava yield data was collected from Ogun State Agricultural Development Program (OGADEP) from 1987 to 2012. Bivariate correlation and regression analysis were conducted using Statistical Package for Social Sciences (SPSS) (Einstein and Abernethy, 2000). The climate variables used in the bivariate correlation analysis included mean annual, seasonal totals and monthly rainfall and temperature (maximum and minimum) during the growing season for the stations of Abeokuta and IjebuOde.

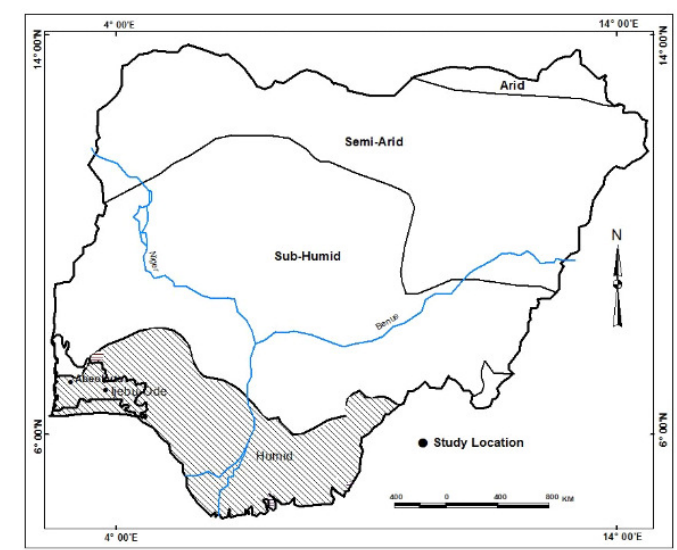

Fig.1: Agro-ecological zones in Nigeria and the study area

The growing season is the period of the rainfall duration from rainfall onset to cessation. It is known as the wet season, which extends from March to October in Southwestern Nigeria (Adejuwon et al., 1990; Bello, 1996; Adejuwon, 2010). In the regression analysis, the dependent variable was the yield of cassava while the independent variables were mean annual rainfall and temperature (maximum and minimum). Z- Distribution analysis shows the spread of cassava yield variables and the significant year of the impact. Z-distribution anomalies are the only valid statistical technique to use when the data is normally distributed (Ayanlade et al, 2010). The cassava yield array was converted to a $\mathrm{Z}$-distribution format varying in magnitude from -3 to +3 . The $Z$-distribution anomaly is mathematically expressed as:

$$
Z-\text { distribution }=\frac{X-\bar{x}}{\sigma}
$$

Where: $\mathrm{X}$ is the annual cassava yield, $\overline{\mathrm{X}}$ is the mean annual cassava yield and $\sigma$ is the standard deviation.

\section{RESULT AND DISCUSSION}

Monthly, seasonal and annual rainfall had no significant relationship with cassava yield in the study area (Tables 1, 2 and 3). The relationship between monthly, seasonal and annual minimum and maximum 
temperatures and cassava yield are not significant at Ijebu-Ode. The only exception is the September maximum temperature that had a positive relationship $(\mathrm{p} \leq 0.05)$ with cassava yield. The relationship $(\mathrm{p} \leq 0.05)$ between monthly minimum (May - $\mathrm{r}=$ 0.483 , June $-r=-0.501$, July $-r=-0.443$, August $-r=$ -0.498 , September $-r=-0.410$ and October $-r=-$ 0.406 ), monthly maximum (May $-\mathrm{r}=-0.532$, July $-\mathrm{r}$ $=-0.523$, August $-\mathrm{r}=-0.599$ and September $-\mathrm{r}=-$ 0.421 ) and cassava yield are negatively significant at Abeokuta (Table 1). Also, the seasonal minimum ( $\mathrm{r}=$ -0.552) and maximum temperatures $(\mathrm{r}=-0.452)$ and cassava yield as well as annual minimum $(\mathrm{r}=-0.431)$ and maximum temperatures $(\mathrm{r}=-.579)$ and cassava yield are negatively significant at Abeokuta (Tables 2 and 3). Negative significance in both minimum and maximum monthly, seasonal and annual temperatures and cassava yield implies that an increase in minimum and maximum monthly, seasonal and annual temperature led to a decrease in cassava yield while positive significance in maximum temperature and cassava yield implies that an increase in maximum temperature led to an increase in cassava yield. Temperature (minimum and maximum) is the climatic element most useful for the yield of cassava. Monthly temperature (minimum and maximum) during the growing season, seasonal and annual temperature are very important in this regard. However, increase in minimum and maximum temperature is detrimental to cassava yield. It was only in the month of September that increase in maximum temperature increases the yield of cassava at Ijebu Ode. This could not be divorced from the fact that rainfall is at its maxima at this period. July and September are the two rainfall maxima months in southwestern Nigeria (Adejuwon, 2010). Monthly temperature data over the years in the study area has shown that there is increase in temperature from August to September. However, the effect of the increased temperature was cushioned by the increased rainfall. The influence of rainfall, maximum temperature and minimum temperature on cassava yield in Ogun state is shown in Table 4. The coefficient of determination $\left(\mathrm{R}^{2}\right)$ is higher in Abeokuta. Annual rainfall and minimum temperature had no significant influence on cassava yield at IjebuOde and Abeokuta. Only maximum temperature had an influence on cassava yield at both Ijebu-Ode and Abeokuta. The coefficient of determination revealed that $7 \%$ of cassava yield was determined by climate variability at Ijebu-Ode.

Table 1: Correlation coefficient (r) between monthly rainfall, minimum temperature, maximum temperature and cassava yield

\begin{tabular}{lllllccccc}
\hline Station & Climate & \multicolumn{9}{c}{ Months } \\
\cline { 2 - 11 } Ijebu- Ode & Variables & Mar & Apr & May & Jun & Jul & Aug & Sept & Oct \\
& Rainfall & 0.032 & -0.178 & -0.285 & 0.281 & 0.012 & -0.123 & 0.285 & 0.166 \\
& Min Temp & -0.005 & -0.101 & -0.03 & 0.096 & 0.006 & -0.025 & -0.007 & 0.108 \\
\multirow{3}{*}{ Abeokuta } & Max Temp & -0.112 & -0.062 & -0.074 & 0.215 & 0.38 & 0.273 & $0.389^{*}$ & 0.124 \\
& Rainfall & 0.106 & -0.181 & 0.141 & -0.126 & -0.249 & -0.238 & -0.248 & 0.149 \\
& Min Temp & -0.312 & -0.293 & $-0.483^{*}$ & $-0.501 * *$ & $-0.443^{*}$ & $-0.498^{* *}$ & $-0.410^{*}$ & $-0.406^{*}$ \\
& Max Temp & -0.305 & -0.332 & $-0.532^{*}$ & -0.371 & $-0.523^{* *}$ & $-0.599^{* *}$ & $-0.421^{*}$ & -0.091 \\
\hline
\end{tabular}

*significant at $\alpha \leq 0.05 ; * *$ significant at $\alpha \leq 0.01$

Table 2: Correlation coefficient (r)) between seasonal Rainfall, Maximum temperature, Minimum temperature and cassava yield

\begin{tabular}{lccc}
\hline Station & Seasonal Rainfall & Min Temperature & Max Temperature \\
\hline Ijebu- Ode & -0.148 & 0 & 0.191 \\
Abeokuta & -0.265 & $-0.452 *$ & $-.552 * *$ \\
\hline \multicolumn{4}{c}{ *significant at $\alpha \leq 0.05 ; * *$ significant at $\alpha \leq 0.01$}
\end{tabular}

Table 3: Correlation coefficient (r) between Annual Rainfall, Maximum temperature, minimum temperature and cassava yield

\begin{tabular}{|c|c|c|c|}
\hline Station & Annual & Min & Max \\
\hline Ijebv-Ode & -0.275 & 0.14 & 0.188 \\
\hline Abeokuta & -0.275 & $-0.431 *$ & $-0.579 * *$ \\
\hline
\end{tabular}

*significant at $\alpha \leq 0.05 ; * *$ significant at $\alpha \leq 0.01$

Table 4: Influence of Rainfall, Maximum Temperature and Minimum Temperature on Cassava yield

\begin{tabular}{lllll}
\hline Station & Regression Model & $\mathbf{R}$ & $\mathbf{R}^{2}$ & $\mathbf{A}$ \\
\hline Ijebu-Ode & $-0.01($ rainfall $)+2.33(\min t e m p)-2.13(\max t e m p)+4.12$ & 0.265 & 0.07 & 0.65 \\
Abeokuta & $-0.04($ rainfall $)-0.78(\min t e m p)-1.54(\max t e m p)+84.87$ & 0.68 & 0.46 & 0.003 \\
\hline
\end{tabular}

The implication is that $93 \%$ of variance in cassava is explainable by other factors than climatic elements. The coefficient of determination revealed that $46 \%$ of cassava yield was determined by climate at Abeokuta. This 
implies that 54\% of variance in cassava yield is explainable by non-climatic factors. Such factors include soil characteristics, farming methods, planting dates, weeds, fertilizer application, pest and diseases, harvesting and so on. Hazell (1984) and Anderson and Hazell \{1987) observed that, adoption of common high-yielding varieties, uniform planting practices, and common timing of field operations, have caused yields of many crops to become more sensitive to the weather, especially in developing countries. Roumasset et al. (1987) and Tollini and Seagraves (1970) argued that increased fertilizer use has had an impact in cassava yield. According to IPCC (2007), the two major climatic elements that affected crop yields and production are reduced amount of rainfall/drought and increased temperature $\left({ }^{\circ} \mathrm{C}\right)$. Rainfall amount, intensity, duration, occurrences, distribution and variability are of paramount importance for plant growth. The daily, weekly and seasonal variability in the value of rainfall is sometimes more important in the determination of the efficiency of crop growth and yield than the mean value. Rainfall has been found to be the most important climatic element in the tropics (Adejuwon, 2008), yet, the monthly, seasonal and annual rainfall had no significant relationship with cassava yield. This shows that rainfall is needed for cassava growth and productivity but not the most important climatic element. Cassava can still produce in the presence of bellow average rainfall. Philips (2005) noted that cassava grows well even in extreme conditions of drought and as such has been called a famine security. Cassava is very tolerant and has the ability to grow on marginal land where other food crops cannot grow well, but for its high yield and productivity, moderate climatic condition and best soil properties like light, sandy loam soil of medium fertility and good aeration or drainage are all crucial (Akanbi and Olabode, 2004). Though, extreme weather conditions such as prolonged drought and excessive amount of rainfall that leads into flood may be detrimental to cassava outputs.

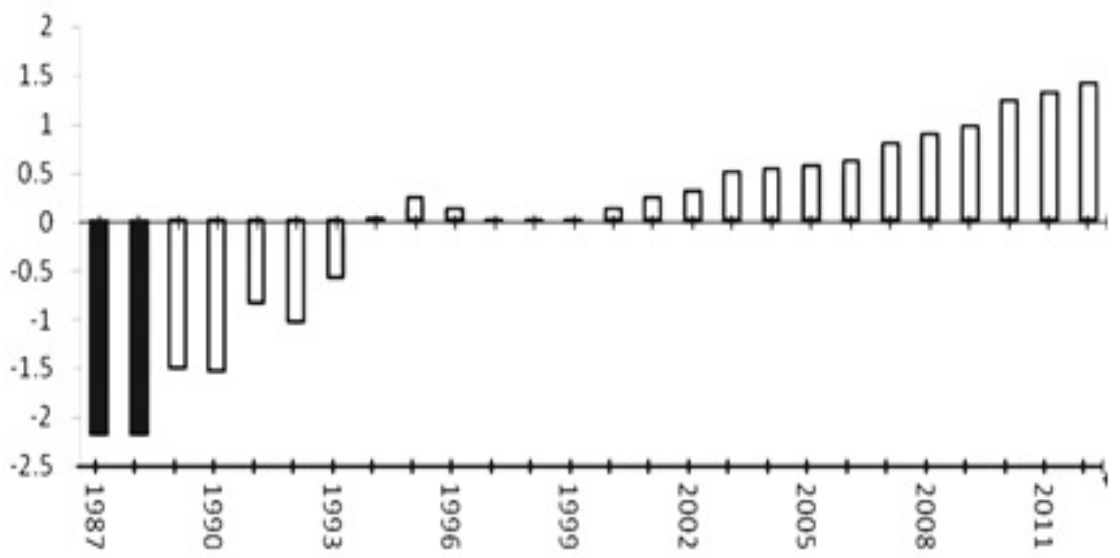

Fig 2: Cassava yield anomalies in Ogun State from 1987 - 2012

Cassava yield anomaly in the study area is shown in Figure 2. The anomalies of cassava yield are negative for 7 years and positive for 19 years during the 26 years of study. Two (2) of the anomalies are significant at $\mathrm{Z} \geq 1.66$ and at $99 \%$ level of significance. This shows that 24 of the anomalies depict ordinary departure from normal yield, which does not impact so much on farmers' means of living. Cassava yield was negatively significant in two years (1987 and 1988) at $p<0.01$ of the 26 years under investigation.

This shows that 24 of the anomalies depict ordinary departure from normal yield, which does not impact so much on farmers' means of living. Casssava yield was mostly favourable to farmers in 2012 when climatic condition appears to be the best. The drought of 1987 makes it the worst year for cassava yield. Rainfall was very low during the early months of the growing season (March to May). The most challenging moment for farmers is the period of significant negative yield.
These years signify cassava yield failure and inadequate food supply, caused by drought. Cai et al, (2009) noted that greater temperature and precipitation variability may lead to more variable soil moisture and crop yield, and larger soil moisture deficit and crop yield reduction are likely to occur more frequently.

Conclusion: This study has shown that monthly, seasonal and annual rainfall do not affect the yield of cassava significantly while monthly, seasonal and annual maximum and minimum temperature affected cassava yield. Non-climatic factors have a greater influence on cassava yield than climatic factors in the study area. The study also revealed that the climatic factors influenced cassava yield more at Abeokuta than Ijebu-Ode. Yield was below average in the early years, with negative significant impact in 1987 and 1988 at $\mathrm{p} \leq 0.01$, but has been on the increase till the end of the investigative period. 


\section{REFERENCES}

Adejuwon, JO (2008). The onset, duration and retreat of rainfall in the Niger Delta Belt, Nigeria. International Journal of Meteorology, UK. 33(333): $303-309$

Adejuwon, JO (2010). Analysis of Rainfall Trend during the Little Dry Season in Southwestern Nigeria. Journal of Meteorology and Climate Science, 8(2):64-70.

Adejuwon, JO; Balogun, EE; Adejuwon, SA (1990). On the annual and seasonal patterns of rainfall fluctuations in sub-Sahara West Africa. International Journal of Climatology, 10: 839848.

Anderson, JR; Hazell, PBR (1987). Variability in Grain Yields: Implications for Agricultural Research and Policy in Developing Countries, Baltimore and London, Published for the International Food Policy Research Institute, The Johns Hopkins University Press.

Ajayi, JO (2014). Comparative Economic Study of Mixed and Sole Cassava Cropping Systems in Nigeria. J. Agris on-line Papers in Economics and Informatics, 6 (4): 15-23

Akanbi, WB; Olabode, OS; Olaniyi, JO; Ojo, AO (2004). Introduction to Tropical Crops. Published by Raflink Compter Eleyele, Ibadan

Ayanlade, A; Odekunle, TO; Orimoogunje, OOI (2010). Impacts of Climate Variability on Tuber crops in Guinea savanna part of Nigeria, A G.I.S approach. Journal of Geography and Geology. 2 (1): 1976-1987

Bello, NJ (1996). An investigation of the characteristics of the onset and cessation of rains in Nigeria. Journal of Theoretical and Applied Climatology, 54: 161-173

Cai, X; Wang, D; Laurent, R (2009) Impact of Climate Change on Crop Yield: A Case Study of Rainfed Corn in Central Illinois. J. Appl. Meteor. Climatol., 48 (9), 1868-1881

Einstein, G; Abernerthy, K (2000). Statistical Package for Social Sciences, SPSS. Version:10.1.Forman University, Greenville SC

Enete, AA; Amusa, TA; Nwobodo, CE (2013). Climate Change and Cassava processing in Southeast Nigeria. Tropicultura, 31.4.272-282
Ezekiel, AA; Olawuyi, SO; Ganiyu, MO; Ojedokun, IK; Adeyemo, SA (2012). Effects of Climate Change on Cassava Productivity in Ilesa East Local Government Area, Osun State, Nigeria. British Journal of Arts and Social Sciences, 10 (II): 153-162

FAO (2004). A cassava industrial revolution in Nigeria; the potential for a new industrial Crop. Food and Agriculture Organization of the United Nations. Rome, Italy.1-66 http://www.fao.org/docrep/007/y5548e/y5548e0 7.htm

FAO (2012). World cassava production. Food and Agriculture Organization of the United Nations. Rome, Italy. www.fao.org/docrep/018/i3278e05.pdf

FAOSTAT (2012). Database of Food and Agriculture Organization of the United Nations. Rome, Italy. http://faostat.fao.org/site/567/DesktopDefault.as px?PageID=567\#ancor. I

Hazell, PBR (1984). Sources of Increased Instability in Indian and U.S. Cereal Production." American Journal of Agricultural Economics 66(1984), 302-11.

IPCC (Inter-Governmental Panel on Climate Change), (2007). The Science Basic. Third Assessment Report in the Inter- governmental Panel on Climate Change. Cambridge University Press, pp.335.

Mearns, LO; Katz, RW; Schneider, SH (1984). Extreme high- temperature events: changes in their probabilities with changes in mean temperature. J. Clim. Appl. Meteorol. 23, 16011613

Nwaobiala, CU; Nwosu, IE (2014). The Effect of IClimate Change on Cassava farmers'Output in Cross river state. Nigeria. International Journal of Agriculture and Development, 17 (1); 1628-1634

Okigbo, BN (1980). Nutritional implications of projects giving high priority to the production of staples of low nutritive quality. The case of cassava in the humid tropics of West Africa. Food and Nutrition Bulletin, 2(4). Tokyo: United Nations University.

Onyenwoke, CA; Simonyan, KJ (2014). Cassava postharvest processing and storage in Nigeria: A 
review. African Journal of Agricultural Research, 9(53): 3853-3863, DOI: 10.5897/AJAR2013.8261

Phillip, DOA (2005). The Potential of Cassava in the Nigerian Economy: The Case of Ogun State. A Paper Presented at the Second Quarterly Business Forum of OCCIMA at Gateway Hotels April, 14, $26 p$.

Pidwirmy, M; Sidney, D (2007). Causes of Climate Change. Encyclopaedia of Earth Eda Cutter I. Develand Washington, D. C. Environmental International Coalition National Council for Science and Environment.

Roumasset, J; Rosegrant, M; Chakravorty, U; Anderson, J (1987). Fertilizer and Crop Yield Variability: A Review." P223-233, Variability in Grain Yields: Implications for Agricultural Research and Policy in Developing Countries, Baltimore and London, Published for the International Food Policy Research Institute, The Johns Hopkins University Press.
Sangpenchan, R (2009). Climate Change Impacts on Cassava Production in Northeastern Thailand. An M.Sc. Thesis. The Pennsylvania State University, U.S

Sowunmi, FA; Akintola, JO (2010). Effect of Climatic Variability on Maize Production in Nigeria. Research Journal of Environmental and Earth Sciences 2(1): 19-30

The Pointer, (29/12/2015). Delta State Aids Federal Government to boost Cassava Production

Tollini, H; Seagraves, JA (1970). Actual and Optimal Use of Fertilizer: The Case of Nitrogen on Corn in Eastern North Carolina. Economic Research Report, Department of Economics, North Carolina State University at Raleigh. 